\title{
Age Nutrition Chirurgie (ANC) study: impact of a geriatric intervention on the screening and management of undernutrition in elderly patients operated on for colon cancer, a stepped wedge controlled trial
}

\author{
Marine Dupuis ${ }^{1 *}$, Elisabetta Kuczewski ${ }^{2}$, Laurent Villeneuve ${ }^{1,3,4}$, Sylvie Bin-Dorel ${ }^{1,3,4}$, Max Haine ${ }^{5}$, Claire Falandry ${ }^{6,7}$,
} Thomas Gilbert ${ }^{5}$, Guillaume Passot ${ }^{6,8}$, Olivier Glehen ${ }^{6,8}$ and Marc Bonnefoy ${ }^{4,5,9}$

\begin{abstract}
Background: Undernutrition prior to major abdominal surgery is frequent and increases morbidity and mortality, especially in older patients. The management of undernutrition reduces postoperative complications. Nutritional management should be a priority in patient care during the preoperative period. However undernutrition is rarely detected and the guidelines are infrequently followed. Preoperative undernutrition screening should allow a better implementation of the guidelines.

Methods/design: The ANC ("Age Nutrition Chirurgie") study is an interventional, comparative, prospective, multicenter, randomized protocol based on the stepped wedge trial design. For the intervention, the surgeon will inform the patient of the establishment of a systematic preoperative geriatric assessment that will allow the preoperative diagnosis of the nutritional status and the implementation of an adjusted nutritional support in accordance with the nutritional guidelines. The primary outcome measure is to determine the impact of the geriatric intervention on the level of perioperative nutritional management, in accordance with the current European guidelines. The implementation of the intervention in the five participating centers will be rolled-out sequentially over six time periods (every six months). Investigators must recommend that all patients aged 70 years or over and who are consulting for a surgery for a colorectal cancer should consider participating in this study.

Discussion: The ANC study is based on an original methodology, the stepped wedge trial design, which is appropriate for evaluating the implementation of a geriatric and nutritional assessment during the perioperative period. We describe the purpose of this geriatric intervention, which is expected to apply the ESPEN and SFNEP recommendations through the establishment of an undernutrition screening and a management program for patients with cancer. This intervention should allow a decrease in patient morbidity and mortality due to undernutrition.
\end{abstract}

Trial registration: This study is registered in ClinicalTrials.gov NCT02084524 on March 11, 2014 (retrospectively registered).

Keywords: Vulnerable, Nutrition, Cancer, Colorectal tumor, Stepped wedge

* Correspondence: marine.dupuis01@chu-lyon.fr

'Unité de Recherche Clinique, Pôle Information Médicale Evaluation

Recherche, Hospices Civils de Lyon, Lyon, France

Full list of author information is available at the end of the article

Biomed Central (c) The Author(s). 2017 Open Access This article is distributed under the terms of the Creative Commons Attribution 4.0 International License (http://creativecommons.org/licenses/by/4.0/), which permits unrestricted use, distribution, and reproduction in any medium, provided you give appropriate credit to the original author(s) and the source, provide a link to the Creative Commons license, and indicate if changes were made. The Creative Commons Public Domain Dedication waiver (http://creativecommons.org/publicdomain/zero/1.0/) applies to the data made available in this article, unless otherwise stated. 


\section{Background}

Colorectal cancer has the third highest incidence of cancer and the second highest mortality. The incidence and mortality curves significantly increase after the age of 55 years, with patients over 70 years old representing $60.5 \%$ of the incidence cases and $75.2 \%$ of cancer deaths $[1,2]$.

While the rates of perioperative morbidity and mortality have been drastically reduced in older patients due to the use of better anesthetic and post-surgical intensive care techniques $[3,4]$, age remains associated with a decrease in overall survival. The main mortality risk factors have recently been evaluated using a multivaried analysis and this predictive model has been prospectively validated on a test sample population [5]. The authors confirmed that the primary mortality risk factor is age: the risk is 1.8 -fold higher between 80 and 85 years while beyond 90 years it is almost 3-fold higher. The increased rate of mortality in older patients compared to younger ones appears to be limited to the early postoperative period, as the disease specific survival ratio after this time is similar to that expected from the age-matched population as a whole [6]. The condition of the perioperative care therefore represents a priority for the improvement of colorectal cancer prognosis in older patients [7-11].

Beyond all the factors that affect the postoperative morbidity and mortality, the nutritional state of the patient is the most important [12]. Undernutrition significantly increases postoperative morbidity-mortality and is responsible for an increase in infectious and non-infectious postoperative complications and in the toxicity linked to the chemotherapy or radiotherapy treatment, leading to a prolongation of patient hospitalization and to an alteration of their quality of life [13].

In the case of colorectal cancer it has been shown that a weight loss greater than $10 \%$ prior to surgery [14] and undernutrition [15] are mortality risk factors. Since the rate of undernutrition is high in older hospitalized patients (up to 50\%) [16-18], a nutritional assessment with undernutrition screening should be performed systematically before surgery in these subjects. The European guidelines, based on the results of many clinical studies (summary in Fig. 1), recommend undernutrition screening and routine nutritional care before, during, and after cancer surgery [3, 4, 19-27]. However, such guidelines with high levels of evidence are rarely followed [28, 29]. An unpublished pilot study that we have recently carried out showed that, in older patients hospitalized for colorectal cancer surgery, undernutrition was screened in less than $30 \%$ of cases and was not exhaustive. Perioperative nutritional care did not conform to the guidelines for over $95 \%$ of those patients undergoing endorectal surgery. Such insufficiency in patient screening and care could either be due to a lack of awareness of this health issue, a lack of interest in nutritional measurements by the medical staff, or by a lack of the necessary knowledge and time to rigorously apply the screening and nutritional care. The French geriatric pathway includes the Geriatric Team (GT), whose expertise is to ensure appropriate care and to improve the management of elderly patients. Our hypothesis is that the systematic intervention of the GT will lead to a better knowledge and respect of the perioperative nutritional care recommendations. This intervention will provide training in good practices, improve undernutrition screening in accordance with the guidelines, improve geriatric and nutritional management in surgery departments. It will also help to promote local paramedic referents via repeated training throughout the length of the study. Several training meetings will improve the identification and care of undernourished patients.

\section{Methods/design Study design}

The ANC protocol is an interventional, comparative, prospective, multicenter, randomized protocol based on the stepped wedge trial design [30,31], which is appropriate for allowing the implementation of a nutritional intervention in older patients by a Geriatric Team (GT) within all participating services. This design involves the sequential rollout of an intervention in centers over several time periods. The order in which the different centers will receive the intervention will be determined at random. The implementation of the intervention in the five participating centers will be rolled-out sequentially over six time periods (every six months), in such a way that each center will initially belong to the "control" arm (without GT intervention) and then to the "intervention" arm (with GT intervention) (Fig. 2). Depending on the center, the pre-intervention phase, as well as the intervention phase, will last from 6 to 30 months. Thus each center will also act as its own control, which will reduce risk of bias and will allow comparison between each support modality (interventional compared to control) and in each group to analyze the effect of time on the effectiveness of an intervention and its learning. The study design will also avoid contamination between patients.

\section{Setting}

The ANC protocol will take place in surgical wards of different French hospitals. Each hospital has its own GT composed of geriatricians and nurses. All the health professionals in the participating surgical wards will be involved in the conduct of the multidisciplinary prevention program (i.e. surgeons, anesthetist, nurses, and nurses assistants). 


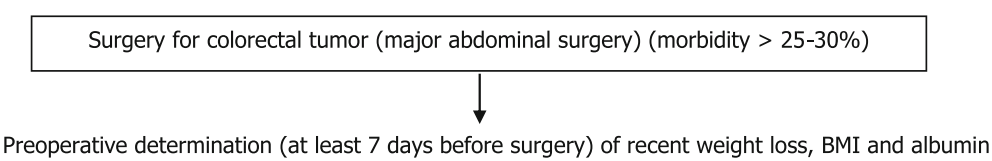

Preoperative determination (at least 7 days before surgery) of recent weight loss, BMI and albumin

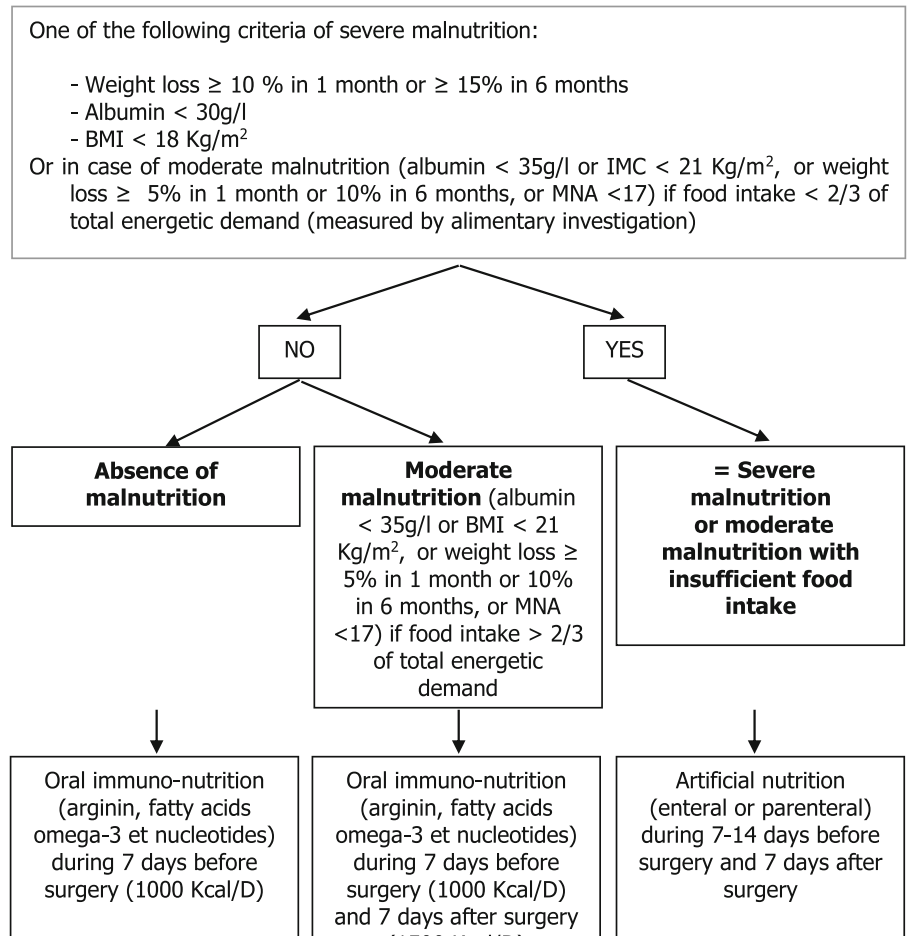

Fig. 1 Recommendations and decision algorithm for the establishment of a nutritional support, according to the current recommendations of the European Society for Clinical Nutrition and Metabolism (ESPEN) and of the French Society of Clinical Nutrition and Metabolism (SFNEP)

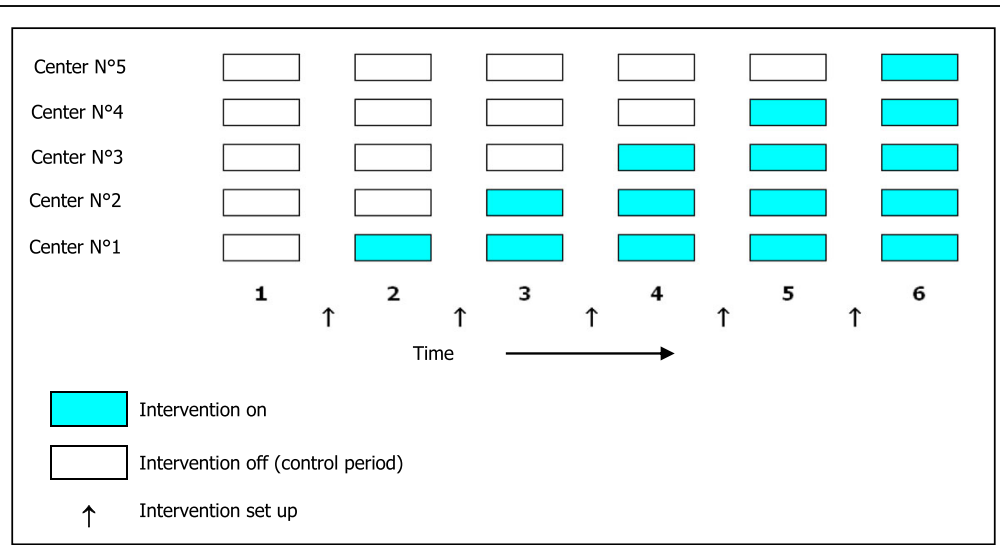

Fig. 2 Schematic representation of the step wedge design of the ANC study: each line represents a center $(n=5)$. Each square represents a time unit (6 months period); white squares: control units (intervention is not yet implemented); blue squares: intervention units (intervention is implemented) 


\begin{tabular}{|c|c|c|}
\hline Inclusion criteria & Non inclusion criteria & Exclusion criteria \\
\hline $\begin{array}{l}\text { - Age } \geq 70 \text { years } \\
\text { - Patient to be hospitalized for } \\
\text { scheduled surgery of a colorectal } \\
\text { tumor with or without } \\
\text { concomitant metastasis } \\
\text { - Patient with social health security } \\
\text { - Patient having given his/her } \\
\text { accord to participate to the study } \\
\text { before any procedure linked to } \\
\text { the study (non opposition) }\end{array}$ & $\begin{array}{l}\text { - Age }<70 \text { years } \\
\text { - Patient hospitalized for } \\
\text { emergency surgical resection of } \\
\text { colorectal tumor with or without } \\
\text { concomitant metastasis } \\
\text { - Patient under legal protection } \\
\text { measure }\end{array}$ & $\begin{array}{l}\text { - Unresectable } \begin{array}{c}\text { colorectal tumor } \\
\text { perioperatively }\end{array} \\
\text { (found } \\
\text { (exceptional case, incidence }< \\
5 \% \text { ) }\end{array}$ \\
\hline
\end{tabular}

Fig. 3 Summary of inclusion, non inclusion and exclusion criteria for the ANC study

\section{Recruitment of patients}

Patients eligible for the ANC study will be all subjects over 70 years old admitted for scheduled surgery of a colorectal tumor with or without concomitant metastasis and having given their informed consent to participate in the study. Patients with an emergency hospitalization for colorectal tumor surgery will not be included. (Fig. 3). Patients who are not included will receive the usual care in accordance with the current practices of the unit.

\section{ANC program}

1. Pre-interventional phase
An observational phase will precede the GT intervention. During this period, patients meeting the inclusion criteria will be included and followed by the digestive surgery unit in accordance with that unit's current practices. Five patients will be included in each center per six months period. This phase will allow the usual practices of nutritional care in each surgical unit to be appraised.

2. Intervention

The intervention provided by the GT will consist of a proposed training which will allow the surgical ward health professionals to follow the nutritional care recommendations and participate in the

Patient information

\section{Preoperative surgical consultation}

- When the intervention is implemented : announcement of a preoperative geriatric consultation

- Pre-surgical assessment with albumin, prealbumin and CRP assays

\begin{tabular}{|l} 
Planned anesthesia consultation and preoperative geriatric \\
consultation \\
- Clinical examination (weight, size) \\
- Results of the following assays : serum albumin, pre-albumin and CRP \\
- Evaluation of: \\
- Nutritional status (BMI, MNA, body weight loss percentage, symptom-based \\
assessment of anorexia (adapted from AC/S-12 of FAACT questionnaire), \\
determination of food intake with respect to total energy needs, albumin \\
assay) \\
- Emotional status (mini-GDS ; GDS) \\
- Functional status (ADL, IADL, fatigue (AVS)), muscle strength (Handgrip \\
strength, SPPB) \\
- Comorbidities (CIRS-G) \\
- Concomitants treatments \\
Nutritional evaluation and nutritional care \\
(see Fig.1)
\end{tabular}

Fig. 4 ANC study flow chart 
preoperative nutritional screening. Furthermore, the GT will propose, upon request from the surgery unit, a systematic implementation of preoperative geriatric assessment leading to a care in geriatric ward if necessary and the identification and training of local paramedical referents.

a. Training of surgical ward staff

The objective is to teach health professionals in order to follow the recommendations of the French National Health Authority ("Haute Autorité de Santé, HAS”), that are issued from the recommendations concerning perioperative nutritional care $[19,20]$, through the diffusion of informative documents and the organization of informative meetings.

b. Systematic implementation of preoperative geriatric assessment

A geriatric assessment is planned at least seven days before surgery. It will be performed by the geriatrician of the GT with four objectives:

1. Assess the patient's history, comorbidities and nutritional status:

Nutritional assessment will be performed according HAS recommendation [1]:

- Notification of a body weight loss $\geq 5 \%$ (10\% for severe cases) in one month,

- And/or Body weight loss $\geq 10 \%$ (15\% for severe cases) in six months,

- Calculation of BMI $<21 \mathrm{Kg} / \mathrm{m}^{2}\left(18 \mathrm{Kg} / \mathrm{m}^{2}\right.$ for severe cases),

- Results of Albumin $<35 \mathrm{~g} / \mathrm{l}$ ( $<30 \mathrm{~g} / \mathrm{l}$ for severe cases),

- Global Mini Nutritional Assessment (MNA) $<17 / 30$.

In addition, each patient will be submitted to a dietetic interview in order to evaluate his daily food intake.

Evans criteria for cachexia diagnostic will be recorded, defined by the association of a body weight loss of $\geq 5 \%$ in 12 months (or BMI $<20 \mathrm{Kg} / \mathrm{m}^{2}$ ) associated with at least three of the following criteria [32]:

- Decrease of muscle strength (hand grip strength $<20 \mathrm{Kg}$ for women and $<30 \mathrm{Kg}$ for men) [33],

- Analogical Visual Scale (AVS) Fatigue score $\leq 3$ [33],

- Anorexic syndrome: defined as a decrease in appetite, responsible of a reduction of total calorie intake $(<20$ $\mathrm{Kcal} / \mathrm{Kg}$ of body weight/day) or a $2 / 3$ reduction of requested food intake evaluated between 14 and 7 days before surgery or a score $\leq 23.5$ on the anorexic scale (adapted from the questionnaire AC/S12 of FAACT) [34],

- Decrease of the Lean Mass Index evaluated by the GT between 14 and 7 days before surgery as a calf circumference $<31 \mathrm{~cm}$ (Mini Nutritional Assessment, MNA; [35]),

- Abnormal biochemical values (1 of the 3 ): CRP $>5.0 \mathrm{mg} / \mathrm{l}$, hemoglobin $<12 \mathrm{~g} / \mathrm{dl}$ (anemia), Serum-albumin $<32 \mathrm{~g} / \mathrm{l}$.

2. and perform a complete clinical examination and a standardized geriatric assessment focusing on:

- Measurement of weight $(\mathrm{Kg})$ and height $(\mathrm{m})$

- Nutritional biologic markers will be systematically collected: albuminemia, pre-albuminemia, C-reactive protein, hemoglobin.

- Assessment of functional status using the Short Physical Performance Battery (SPPB) [36], the Activity Daily Life (ADL, [37]) and the Instrumental Activity Daily Life (IADL, [38]).

- Assessment of emotional status using the Geriatric Depression Scale (GDS, [39])

- Assessment of co-morbidities (CIRS-G test)

3. propose an adapted preoperative nutritional management according to the nutritional status of the patient using the decision tree for nutritional care [20];

4. advise the surgery team of the nutritional recommendations to follow in the postoperative phase (Fig. 1).

\section{ANC study schedule}

In each surgical department involved in the study, the surgeon will screen all patients for trial eligibility during a preoperative surgical consultation. Patients in the observational period will receive the usual care, in accordance with the current practices of the unit. In the interventional period, the surgeon will inform the patient of a systematic preoperative geriatric assessment.

For the implementation of the intervention, the GT assessment will be standardized for all centers. It will last approximately $90 \mathrm{~min}$ and will be carried out by the GT team, together with a dietician, in the surgery or anesthesia unit, depending on the practices of the center. A nutritional management plan, adapted to the nutritional status of the patient, will be prescribed and implemented following this assessment, in accordance with the current recommendations and decision algorithm (Fig. 4).

\section{Outcome and measurement}

The primary outcome measure is to determine the impact of the geriatric intervention on the level of perioperative 
nutritional management, in accordance with the current European guidelines, of patients aged 70 years old or above who are undergoing surgery for colorectal cancer. This will be accomplished by evaluating the percentage of patients having received a nutritional screening i.e. measurement of body weight and size, calculation of the body mass index (BMI), evaluation of a recent body weight loss and an albumin assay at least 7 days before surgery, and having received oral immunonutrition during 7 days before surgery (if absence of malnutrition) or immunonutrition during 7 days before and 7 days after surgery (if moderate malnutrition) or artificial nutrition during 7-14 days before surgery and 7 days after surgery.

The secondary outcomes are:

1. The percentage of patients having received a nutritional screening, i.e. measurement of body weight and size, calculation of the body mass index (BMI), evaluation of a recent body weight loss and an albumin assay at least 7 days before surgery.

2. The percentage of patients having received oral immuno-nutrition

3. The percentage of patients with undernutrition, severe undernutrition and cachexia

4. The rate and type of postoperative complications, from grade I to $\mathrm{V}$, according to the Common Terminology Criteria for Adverse Events v4.0 (CTCAE) of National Cancer Institute, occurring up to 30 days after surgery.

5. The number of actual oral nutritional supplements intakes with respect to planned ones (noted in the patient diary given at the preoperative geriatric assessment).

6. The comparison of functionality scores obtained on the ADL and IADL, evaluated by the GT between the beginning (between 14 and 7 days before surgery) versus the end (after surgery, the day before or the day of discharge from the surgical ward) of the hospitalization period.

7. The emotional state of the patient evaluated with the mini-GDS (score on 4) and the GDS 15 (if mini GDS score $>2$ ).

8. The number of concomitant treatments (number of drug specialties between 0 and 3 , between 3 and 6 , over 6) during the hospitalization period.

\section{Data collection}

The data for the CRF (Case Report Form) will be collected and recorded by the Clinical Research Assistant (CRA) from the patients' medical files.

\section{Sample size}

The sample size was defined using the appropriate formula for stepped wedge studies [30]. It was calculated by considering the most unfavorable situation that would result in a statistical difference, i.e $5 \%$ of pre- and post-operatively nutritional management in accordance with the current European guidelines in the control group vs. $20 \%$ in the intervention group. The significance threshold was fixed at $5 \%$. The number of centers is 5 and the number of time period has been set at 6 to obtain optimum power. The coefficient of variation should be between 0.15 and 0.40 , we set at 0.40 to be in the most pessimistic conditions. Five patients per center/step will be required for a power of $84 \%$. This corresponds to a total of 150 patients (30 for each center).

\section{Statistical analysis}

In order to ensure the objectivity of the results, the statistical analysis for this study will be performed by an independent statistician at the end of the follow-up period of the last patient included. The data will be analyzed using the SAS 9.1 software (Cary Inc., North Carolina, USA). No intermediate analysis is planned. Confidence intervals will be calculated according to an alpha risk of $5 \%$ and the statistical test results will be given a $5 \%$ threshold.

Univariate descriptive analysis will be used. The patients' characteristics will be described and compared between the subsequent time points of the centers in which the intervention has started (intervention group) and those in which it has not (control group). The analysis will concern the patients' demographic (age, sex) and clinical (antecedents and associated illnesses, surgical indication, etc.) characteristics, as well as the type and location of the intervention that has been performed. The comparisons will be evaluated using the Student $t$-test or the corresponding nonparametric test for the quantitative variables (average comparisons) and the Chi-Square or the Fisher's test for the qualitative variables (percentage comparisons).

Concerning the primary endpoint analysis, the nutritional management of pre- and postoperative rate according with the recommendations will be compared before and after implementation of the intervention. This comparison will be performed by a logistic regression integrating time and the group (intervention / control) and an adjustment on the group (GLMM = generalized linear mixed model).

The support levels before and after implementation of the intervention will be presented on a gross basis and compared using a Chi square test. A graphical analysis will view the support levels before and after implementation of the intervention for each of the centers.

Concerning the analysis of secondary outcomes:

The percentage of subjects who underwent screening and the percentage of patients who received a care prescription will also be compared using a GLMM. 
Globally (without taking into account the intervention) will be described:

* malnourished subjects, malnourished subjects who could not get a prescription for nutritional management, severe malnourished patients, cachectic subjects among all subjects who underwent screening (percentage and 95\% confidence interval)

* the emotional score, the mini GDS on subjects who received screening, the number of concomitant treatments and specialties, the number of food intake on the number of prescribed taken, the average change in IADL score (mean, standard deviation, median, minimum, maximum).

The percentage of complications will also be compared between subjects who received nutritional support and those who don't have benefited of this support by a Chi square test.

\section{Ethical considerations}

Investigators must recommend that all patients aged 70 years old or over, consulting for a surgery for colorectal cancer, should consider participating in this study. There should be no pre-selection of the patients by the surgeon. The participating patients will give their consent after being told about the study. Their decision to accept or refuse participation will not affect their medical and nursing care.

\section{Trial status}

The enrolment of patients has begun, but data cleaning or analysis had not yet begun as of this article's submission.

\section{Discussion}

\section{Discussion of the study design}

The ANC study is based on an original methodology, the stepped wedge trial design which differs from the parallel and cross-over designs and presents several advantages. Due to the type of the intervention, the risk of contamination would have been too high with a one to one randomization, hence the need for clusters. The stepped wedge design may require fewer centers than a parallel group design to ensure similar group comparability [30, 31, 40-42].

This type of study design presents benefits with regard to implementation: the sequential introduction of the intervention in all the centers does not disadvantage any particular center. The implementation will be easier and it can facilitate the organization of the study in routine practice [43].

Moreover, the risk of center bias is minimized because each center is its own control and receives the intervention. Therefore, the impact of the intervention can be estimated from both between and within center comparisons [30, 31, 40, 44].

This design also allows an evaluation of the effects of time period on protocol effectiveness (following the temporal evolution of the application of the recommendations in the centers). Centers will differ in the time spent on the intervention. Centers that switch at the first time period will be more experienced with the ANC intervention than centers that switch at last time period [44].

Finally, the stepped wedge design allows each participating center to benefit from the ANC intervention. This opportunity is a motivational factor for taking part in this study. In accordance with good ethical practice, the intervention is expected to do more good than harm.

\section{Discussion of the intervention}

The principal aim of this study is to increase the implementation of the recommendations for perioperative nutritional care for colorectal cancer in elderly patients [19, 20]. In spite of their importance, such recommendations are rarely followed $[28,29]$. Our suggestion is that the intervention of the geriatric team (GT) in the perioperative period will help to reduce post-surgical complications and the associated mortality - morbidity. Consequently, the application of the ANC protocol could also lead to a reduction in the length of the post-surgical hospital stay. The ANC study will also develop or strengthen the collaboration between surgical wards and the GT, and the application of actual nutritional recommendations should improve during and after the study.

The introduction of GT in the majority of multidisciplinary hospitals should improve the level of awareness and knowledge of undernutrition-related problems in elderly patients hospitalized for surgery through the training provided by the GT in the wards. It should allow a comprehensive and systematic screening for undernutrition in elderly patients hospitalized for colorectal cancer based on the knowledge of patient weight loss, body mass index, albumin concentration and MNA. It could also promote the application of the good practice recommendations (HAS, ESPEN, SFNEP) and help to develop collaboration and communication among health professionals. Furthermore, in case of severe undernutrition, a specific treatment including artificial nutrition should be discussed in accordance with the recommendations. It is also important to take care of patients with moderate undernutrition in order to prevent the establishment of cachexia.

In summary, the modification of practices induced by the ANC study should allow a decrease in undernutritionrelated morbidity and mortality in patients, as well as a decrease in the cost of hospitalization (shortening of the stay and reduction of complications).

Finally, after the completion of the ANC study, the maintenance of the implemented intervention (awareness, 
collaboration, support, nutritional status diagnosis and nutritional care) and the dissemination of the results will be proposed so that this type of intervention can be extended to other wards and to other types of surgery.

\section{Abbreviations}

ADL: Activity daily life; ANC: Age Nutrition Chirurgie; AVS: Analogical visual scale; BMI: Body mass index; GDS: Geriatric depression scale; GT: Geriatric team; IADL: Instrumental activity daily life; MNA: Mini nutritional assessment; SPPB: Short physical performance battery

\section{Acknowledgements}

The authors acknowledge the digestive surgery and geriatric teams of Jean Mermoz Hospital, Leon Berard Center, Protestant Infirmary, Saint Joseph-Saint Luc Hospital and Hospices Civils de Lyon (Edouard Herriot, Croix-Rousse and Lyon Sud) who contribute to patient enrollment in this study.

\section{Funding}

This study is supported by a grant from the French ministry of health (PREQHOS-2011).

\section{Availability of data and materials}

Not applicable.

\section{Authors' contributions}

The chief investigator of the study, MB, as well as EK, SBD, LV, MD, MH, CF, $\mathrm{TG}, \mathrm{GP}$ and $\mathrm{OG}$, were responsible for determining the research question, the design, methodology and follow-up of the study; obtaining ethics approval; acquiring financial support and writing the paper. SBD contributed to the fine-tuning of the methodology and statistical analysis. All authors helped draft and revise the manuscript and approved the final version.

\section{Competing interests}

The authors declare that they have no competing interests.

\section{Consent for publication}

Not applicable.

\section{Ethics approval and consent to participate}

The study protocol was approved by the Institutional Review Board: the Sud Est 2 ethics committee on the 21th November 2012. The Ethical approval was given for all participating centres. The research carried out will be on accordance with the Helsinki Declaration and ICH GCP Guidelines. The study complies with the principles of the Data Protection Act. The study has been registered on the ClinicalTrial.gov website under the identification number NCT02084524

\section{Author details}

'Unité de Recherche Clinique, Pôle Information Médicale Evaluation Recherche, Hospices Civils de Lyon, Lyon, France. ${ }^{2}$ Service d'Hygiène Épidémiologie Infectiovigilance et Prévention, Hospices Civils de Lyon, Lyon, France. ${ }^{3}$ Université de Lyon, EAM Parcours Santé Systémique, 4128 Lyon, France. ${ }^{4}$ Université Lyon 1, Lyon, France. ${ }^{5}$ Service de Médecine Gériatrique, Centre Hospitalier Lyon-Sud, Hospices Civils de Lyon, Pierre-Bénite, France. ${ }^{6}$ Université Lyon 1, EMR 3738, Oullins, France. ${ }^{7}$ Oncologie Médicale, Centre d'Investigation des Thérapeutiques en Oncologie et Hématologie de Lyon (CITOHL), Centre Hospitalier Lyon-Sud, Institut de Cancérologie des Hospices Civils de Lyon (IC-HCL), Lyon, France. ${ }^{8}$ Service de Chirurgie Viscérale et Endocrinienne, Centre Hospitalier Lyon-Sud, Hospices Civils de Lyon, Pierre-Bénite, France. ${ }^{9}$ INSERM U1060, Laboratoire CarMeN (cardiovasculaire, métabolisme, diabétologie et nutrition), Université Claude Bernard Lyon 1, Pierre-Bénite, France.

Received: 27 July 2016 Accepted: 21 December 2016 Published online: 07 January 2017

\section{References}

1. HAS. Stratégie de prise en charge en cas de dénutrition protéinoénergétique chez la personne âgée. 2007.
2. Bélot A, Velten M, Grosclaude P, et al. In: Saint-Maurice (Fra), editor. Estimation nationale de l'incidence et de la mortalité par cancer en France entre 1980 et 2005. Luxembourg: Institut National de Veille Sanitaire; 2008.

3. Gianotti L, Braga M, Nespoli L, Radaelli G, Beneduce A, Di Carlo V. A randomized controlled trial of preoperative oral supplementation with a specialized diet in patients with gastrointestinal cancer. Gastroenterology. 2002;122:1763-70.

4. Arends J, Bodoky G, Bozzetti F, et al. ESPEN Guidelines on Enteral Nutrition: Non-surgical oncology. Clin Nutr. 2006;25:245-59.

5. Heriot AG, Tekkis PP, Smith JJ, et al. Prediction of postoperative mortality in elderly patients with colorectal cancer. Dis Colon Rectum. 2006;49:816-24.

6. Alley PG. Surgery for colorectal cancer in elderly patients: a systematic review. Colorectal Cancer Collaborative Group. Lancet. 2000;356:968-74.

7. Berger DH, Roslyn JJ. Cancer surgery in the elderly. Clin Geriatr Med. 1997; 13:119-41.

8. Luo R, Giordano SH, Zhang DD, Freeman J, Goodwin JS. The role of the surgeon in whether patients with lymph node-positive colon cancer see a medical oncologist. Cancer. 2007;109:975-82.

9. Davidoff AJ, Rapp T, Onukwugha E, et al. Trends in disparities in receipt of adjuvant therapy for elderly stage III colon cancer patients: the role of the medical oncologist evaluation. Med Care. 2009;47:1229-36.

10. Martinez SR, Chen SL, Bilchik AJ. Treatment disparities in Hispanic rectal cancer patients: a SEER database study. Am Surg. 2006;72:906-8.

11. Kemeny MM, Busch-Devereaux E, Merriam LT, O'Hea BJ. Cancer surgery in the elderly. Hematol Oncol Clin North Am. 2000;14:169-92.

12. Blanc-Bisson C, Fonck M, Rainfray M, Soubeyran P, Bourdel-Marchasson I. Undernutrition in elderly patients with cancer: target for diagnosis and intervention. Crit Rev Oncol Hematol. 2008;67:243-54.

13. Dewys WD, Begg C, Lavin PT, et al. Prognostic effect of weight loss prior to chemotherapy in cancer patients. Eastern Cooperative Oncology Group. Am J Med. 1980;69:491-7.

14. Alves A, Panis Y, Mathieu P, Mantion G, Kwiatkowski F, Slim K. Postoperative mortality and morbidity in French patients undergoing colorectal surgery: results of a prospective multicenter study. Arch Surg. 2005;140:278-83. discussion 84

15. Gupta D, Lammersfeld CA, Burrows JL, Dahlk SL, Vashi PG, Grutsch JF, Hoffman S, Lis CG. Bioelectrical impedance phase angle in clinical practice: implications for prognosis in advanced colorectal cancer. Am J Clin Nutr. 2004;80(6):1634-8

16. Lansey S, Waslien C, Mulvihill M, Fillit $\mathrm{H}$. The role of anthropometry in the assessment of malnutrition in the hospitalized frail elderly. Gerontology. 1993:39:346-53.

17. Farrer K, Donaldson E, Blackett B, Lloyd H, Forde C, Melia D, Lal S. Nutritiona screening of elderly patients: a health improvement approach to practice. J Hum Nutr Diet. 2013:27:184-191.

18. Winter J, Flanagan D, McNaughton SA, Nowson C. Nutrition screening of older people in a community general practice, using the MNA-SF. J Nutr Health Aging. 2013;17(4):322-5

19. Weimann A, Braga M, Harsanyi $L$, et al. ESPEN Guidelines on Enteral Nutrition: Surgery including organ transplantation. Clin Nutr. 2006;25:224-44.

20. SFNEP. Arbre décisionnel du soin nutritionnel, accessed at: http://www. sfnep.org/images/stories/pdf_NCM/NCM_arbre_dedeci_23_04.pdf.

21. Senesse $P$, Assenat E, Schneider S, et al. Nutritional support during oncologic treatment of patients with gastrointestinal cancer: who could benefit? Cancer Treat Rev. 2008;34:568-75.

22. Braunschweig CL, Levy P, Sheean PM, Wang X. Enteral compared with parenteral nutrition: a meta-analysis. Am J Clin Nutr. 2001;74:534-42.

23. Elia M, Van Bokhorst-de van der Schueren MA, Garvey J, et al. Enteral (oral or tube administration) nutritional support and eicosapentaenoic acid in patients with cancer: a systematic review. Int J Oncol. 2006;28:5-23.

24. Wu GH, Liu ZH, Wu ZH, Wu ZG. Perioperative artificial nutrition in malnourished gastrointestinal cancer patients. World J Gastroenterol. 2006;12:2441-4.

25. Lewis SJ, Egger M, Sylvester PA, Thomas S. Early enteral feeding versus "nil by mouth" after gastrointestinal surgery: systematic review and metaanalysis of controlled trials. BMJ. 2001;323:773-6.

26. Heyland DK, Novak F, Drover JW, Jain M, Su X, Suchner U. Should immunonutrition become routine in critically ill patients? A systematic review of the evidence. JAMA. 2001;286:944-53.

27. Beale RJ, Bryg DJ, Bihari DJ. Immunonutrition in the critically ill: a systematic review of clinical outcome. Crit Care Med. 1999;27:2799-805. 
28. Chaufour-Andre C, Fingal C, Roux P, et al. Conséquences nutritionnelles de la chirurgie en oncogériatrie (toutes chirurgies). 2008.

29. Spiro A, Baldwin C, Patterson A, Thomas J, Andreyev HJ. The views and practice of oncologists towards nutritional support in patients receiving chemotherapy. Br J Cancer. 2006;95:431-4.

30. Brown CA, Lilford RJ. The stepped wedge trial design: a systematic review. BMC Med Res Methodol. 2006;6:54.

31. Hussey MA, Hughes JP. Design and analysis of stepped wedge cluster randomized trials. Contemp Clin Trials. 2007;28(2):182-91.

32. Evans WJ, Morley JE, Argiles J, et al. Cachexia: a new definition. Clin Nutr. 2008;27:793-9.

33. Boyd CM, Xue QL, Simpson CF, Guralnik JM, Fried LP. Frailty, hospitalization, and progression of disability in a cohort of disabled older women. Am J Med. 2005;118:1225-31.

34. Muscaritoli M, Anker SD, Argiles J, et al. Consensus definition of sarcopenia, cachexia and pre-cachexia: joint document elaborated by Special Interest Groups (SIG) "cachexia-anorexia in chronic wasting diseases" and "nutrition in geriatrics". Clin Nutr. 2010;29:154-9.

35. Kaiser MJ, Bauer JM, Ramsch C, et al. Validation of the Mini Nutritional Assessment short-form (MNA-SF): a practical tool for identification of nutritional status. J Nutr Health Aging. 2009;13:782-8.

36. Guralnik JM, Simonsick EM, Ferrucci L, et al. A short physical performance battery assessing lower extremity function: association with self-reported disability and prediction of mortality and nursing home admission. J Gerontol. 1994;49:M85-94.

37. Katz S, Akpom CA. 12. Index of ADL. Med Care. 1976;14:116-8.

38. Graf C. The Lawton instrumental activities of daily living scale. Am J Nurs. 2008:108:52-62. quiz -3.

39. Brown LM, Schinka JA. Development and initial validation of a 15-item informant version of the Geriatric Depression Scale. Int J Geriatr Psychiatry. 2005:20:911-8

40. Mouchoux C, Rippert P, Duclos A, Fassier T, Bonnefoy M, Comte B, Heitz D, Colin C, Krolak-Simon P. Impact of a multifaceted program to prevent postoperative delirium in the elderly: the CONFUCIUS stepped wedge protocol. BMC Geriatr. 2011;11:25.

41. Copas AJ, Lewis JJ, Thompson JA, Davey C, Baio G, Hargreaves JR. Designing a stepped wedge trial: three main designs, carry-over effects and randomization approaches. Trials. 2015;16:352.

CrossRefPubMedPubMedCentral.

42. Woertman W, de Hoop E, Moerbeek M, Zuidema SU, Gerritsen DL, Teerenstra S. Steped wedge designs could reduce the required sample size in cluster randomized trials. J Clin Epidemiol. 2013;66(7):752-8. CrossRefPubMed.

43. Mdege ND, Man MS, Taylor Nee Brown CA, Torgerson DJ. Systematic review of stepped wedge cluster randomized trials shows that design is particularly used to evaluate interventions during routine implementation. J Clin Epidemiol. 2011;64(9):936-48. CrossRefPubMed.

44. Occelli P, Touzet S, Rabilloud M, Ganne C, Poupon Bourdy S, Galamand S, Debray M, Dartiguepeyrou A, Chuzeville M, Comte B, Turkie B, Tardy M, Luiggi J-S, Jacquet-Francillon T, Gilbert T, Bonnefoy M. Impact of a transition nurse program on the prevention of thirty-day hospital readmissions of elderly patients discharged from short-stay units: study protocol of the PROUST stepped-wedge cluster randomised trial. BMC Geriatr. 2016;16:57.

\section{Submit your next manuscript to BioMed Central and we will help you at every step:}

- We accept pre-submission inquiries

- Our selector tool helps you to find the most relevant journal

- We provide round the clock customer support

- Convenient online submission

- Thorough peer review

- Inclusion in PubMed and all major indexing services

- Maximum visibility for your research

Submit your manuscript at www.biomedcentral.com/submit
C) Biomed Central 